\title{
Gentisate-1,2-dioxygenase activity by an iron(II)-phenanthroline complex
}

\author{
ABHRANIL DE ${ }^{\mathrm{a}}$, DHANANJAY DEY ${ }^{\mathrm{a}}$, AJIT DAS $^{\mathrm{b}}$, NIRANJAN KOLE ${ }^{\mathrm{a}}$ and \\ BHASKAR BISWAS ${ }^{\mathrm{a}, \mathrm{c}, *}$ \\ ${ }^{a}$ Department of Chemistry, Raghunathpur College, Purulia, West Bengal 723 133, India \\ ${ }^{b}$ Department of Chemistry, Sidho-Kanho-Birsha University, Purulia, West Bengal 723 104, India \\ ${ }^{c}$ Department of Chemistry, Surendranath College, 24/2 M G Road, Kolkata, West Bengal 700 009, India \\ E-mail: mr.bbiswas@rediffmail.com; icbbiswas@gmail.com
}

MS received 21 October 2017; revised 17 January 2018; accepted 23 January 2018; published online 28 February 2018

\begin{abstract}
In this work, we have synthesised and crystallographically characterized a mononuclear iron(II) complex, $\left[\mathrm{Fe}(\text { phen })_{3}\right]\left(\mathrm{NO}_{3}\right)_{2} \cdot 2 \mathrm{H}_{2} \mathrm{O}(\mathbf{1})$ (phen $=1,10$-phenanthroline). Single crystal X-ray diffraction (SXRD) analysis revealed that $\mathbf{1}$ crystallizes in monoclinic system with $P 1^{-}$space group. The lattice water molecules in 1 form a water-nitrate cluster, $\left(\mathrm{H}_{2} \mathrm{O}\right)_{2}\left(\mathrm{NO}_{3}\right)_{2}$ through strong H-bonding interaction mediated via iron(II) complex in a unique binding motif and provide additional stability to the compound in the solid state. This iron(II) complex is able to catalyze the cleavage of aromatic $\mathrm{C}$-C linkage of 2,5-dihydroxybenzoic acid (Gentisic acid, $\mathrm{GA}$ ) in oxygen environment. The iron(II) complex in the presence of two equivalent of triethylamine ( $\mathrm{Et}_{3} \mathrm{~N}$ ) binds with GA stoichiometrically in acetonitrile medium at $25^{\circ} \mathrm{C}$. Observation of GA-to-iron LMCT optical bands at 521 and $609 \mathrm{~nm}$ supports in situ generated iron-GA adduct in solution. This in situ generated iron-GA adduct reacts with molecular oxygen at the rate, $k_{\mathrm{obs}}=6.58 \times 10^{-3} \mathrm{~min}^{-1}$ in acetonitrile and affords exclusively 2-oxo-4-hydroxy-hepta-3,5-dienedioic acid. The incorporation of both the oxygen atoms of molecular oxygen in the bio-mimicking activity of gentisate-1,2-dioxygenase by this iron(II)-phenanthroline complex remain a rare example in scientific literature.
\end{abstract}

Keywords. Iron(II); phenanthroline; X-ray structure; gentisate-1,2-dioxygenase activity; bio-mimicking chemistry.

\section{Introduction}

Iron(II) complexes containing $\mathrm{N}$-donor ligands not only help to enrich molecular library but also bring a new source of light to unveil different mechanistic fate related to organic transformations in chemical and biological sciences. ${ }^{1-3}$ Investigation of physicochemical properties of these iron(II) complexes leads to important information to develop the science of living world. Among the different organic transformations in chemical and biological sciences, aerobic degradation of aromatic compounds by iron complexes remains a very difficult challenge to the chemists. ${ }^{4-6}$ Especially, iron-based bio-models relevant to important microorganisms in biochemistry provide significant insights towards aromatic ring-fission of substrates like catechol, protocatechuate, homoprotocatechuate, hydroquinone, gentisate or homogentisate (or their substituted derivatives). ${ }^{7-9}$ 2,5-dihydroxybenzoic acid, which is commonly known as Gentisic acid is a key intermediate in aerobic bacterial pathways for the metabolism of a large number of aromatic compounds, including anthranilate, $\beta$-naphthol, 4-hydroxy benzoates, flavonones, salicylate, etc. ${ }^{10}$ Among these aromatic ring cleavage enzymes, gentisate 1,2-dioxygenase from Pseudaminobacter salicylatoxidans BN12 (P. salicylatoxidans) appears to be most versatile since it is able to convert a wide range of substituted salicylates with the highest order of enzymatic activities. ${ }^{11,12}$ The cell using gentisate derives carbon and energy from direct or indirect conversion of maleylpyruvate to metabolites. ${ }^{13}$ During the investigation of oxygen activation

\footnotetext{
*For correspondence

Electronic supplementary material: The online version of this article (https://doi.org/10.1007/s12039-018-1425-4) contains supplementary material, which is available to authorized users.
} 
of 2,5-dihydroxybenzoic acid using iron complexes as catalysts, the aromatic ring-cleavage occurs generally in 1,2-position ${ }^{14}$ with the formation of dicarboxylic acids and the presence of hydroxyl/amino groups in the substrate assist to activate the aromatic ring for the electrophilic attack of the dioxygen molecule during such dioxygenase activities. Further, it is commonly seen that catalytic iron(III) complexes lead to intra-diol cleaving products while iron(II) complexes lead to the production of extra-diol cleaving products. ${ }^{15-19}$

In many $\left[\mathrm{FeN}_{6}\right]^{2+}$ systems, the cationic low spin $[\mathrm{Fe}$ $\left.\left(2,2^{\prime} \text {-bipyridine }\right)_{3}\right]^{2+}$ or $\left[\mathrm{Fe}\left(2,2^{\prime}, 2^{\prime}, 6^{\prime} \text {-terpyridine }\right)_{2}\right]^{2+}$ ions, ${ }^{20}$ remain important examples for the spin cross over systems, tris(6-methyl-2,2'-bipyridine) iron(II) and bis(2,4-bis(pyridin-2-yl)thiazole)iron(II) ions. ${ }^{21}$ In our recent work, we have synthesized and structurally characterized similar iron(II)-phenanthroline complex, $\left[\mathrm{Fe}(1,10 \text {-phenanthroline })_{3}\right] \mathrm{Cl}_{2}$ and explored its catalytic activity towards catechol dioxygenase functionality. ${ }^{6}$ Herein, we report the synthesis and structural characterization of a new ferroin analogue, $\left[\mathrm{Fe}(1,10 \text {-phenanthroline })_{3}\right]\left(\mathrm{NO}_{3}\right)_{2} \cdot 2 \mathrm{H}_{2} \mathrm{O}(\mathbf{1})$. The lattice water molecules showed unique binding motifs in forming a novel water-nitrate cluster mediated via metal complex which provide additional stability to the solid. This iron(II) complex has been evaluated as a functional model to mimic the catalytic cycles of gentisate-1,2dioxygenase enzyme in acetonitrile medium and it is found that iron(II) catalyst exclusively produced 2-oxo4-hydroxy-hepta-3,5-dienedioic acid at the rate, $k_{\mathrm{obs}}=$ $6.58 \times 10^{-3} \mathrm{~min}^{-1}$.

\section{Experimental}

\subsection{Materials}

High purity 1,10-phenanthroline (E Merck, India), ferric nitrate nonahydrate (Alfa-Aesar, UK), 2,5-dihydroxy benzoic acid (Sigma Aldrich, USA) were used as purchased. All other chemicals and solvents were of analytical grade and were used as received without further purification.

\subsection{Synthesis of $\left[\mathrm{Fe}(\text { phen })_{3}\right]\left(\mathrm{NO}_{3}\right)_{2} \cdot 2 \mathrm{H}_{2} \mathrm{O}(\mathbf{1})$}

An aqueous solution of phenanthroline $(0.540 \mathrm{~g}, 3 \mathrm{mM}$ in 15 $\mathrm{mL}$ ) was added dropwise to an aqueous solution of $\mathrm{Fe}\left(\mathrm{NO}_{3}\right)_{3}$ $9 \mathrm{H}_{2} \mathrm{O}(0.404 \mathrm{~g}, 1 \mathrm{mM}$ in $10 \mathrm{~mL})$ and stirred the solution for $30 \mathrm{~min}$. The dark blue coloured solution was kept in air for slow evaporation to obtain the crystalline product.

Yield: $\sim 0.750 \mathrm{~g}(\sim 66 \%$ based on metal salt $)$. Anal. Calc. for $\mathrm{C}_{36} \mathrm{H}_{28} \mathrm{~N}_{8} \mathrm{O}_{8} \mathrm{Fe}(\mathbf{1})$ : C, 57.16; H, 3.73; N, 14.81\%. Found: C, 57.06; H, 3.66; N, 14.78\%. IR (KBr, cm $\left.{ }^{-1}\right)$ : 1621, 1606 $\left(\mathrm{v}_{\mathrm{C}=\mathrm{N}}\right), 1384,\left(\mathrm{v}_{\mathrm{NO} 3}-\right), 3541 \& 3487\left(\mathrm{v}_{\mathrm{O}-\mathrm{H}}\right)$; UV-Vis $\left(\lambda_{\max }\right.$, $\mathrm{nm}, 10^{-4} \mathrm{M}, 1 \mathrm{~cm}$ optical pathlength, Abs, MeCN): 269 (1.27), 293 (0.83), 319 (0.37), 515 (0.51); EI-MS (MeCN): $\mathrm{m} / \mathrm{z}, 597.41\left[1+\mathrm{H}^{+}\right]^{+}$.

\subsection{Physical measurements}

Elemental analyses (carbon, hydrogen and nitrogen) were performed on a Perkin-Elmer 2400 CHNS/O elemental analyzer. Fourier Transform Infrared (FT IR) spectra (KBr discs, $4000-300 \mathrm{~cm}^{-1}$ ) were recorded using an FTIR-8400S SHIMADZU spectrophotometer in the range $400-3600 \mathrm{~cm}^{-1}$. Ground-state absorption measurements were made with a JASCO model V-730 UV-Vis spectrophotometer. The ${ }^{1} \mathrm{H}$ nuclear magnetic resonance (NMR) spectra were recorded on a Bruker DPX-500 MHz spectrometer. The Electron Paramagnetic Resonance (EPR) spectrum was recorded on a Bruker EMX-X band spectrometer. Electrospray ionization (EI) mass spectrum was recorded using a Q-tofmicro quadruple mass spectrometer. Molar conductivity was recorded using a Metler conductivity meter. A Gouy balance was used to determine the magnetic moments of the powdered samples, employing $\mathrm{Hg}$ (II) tetrathiocyanatocobaltate(II) as a calibrant. Diamagnetic corrections were made from Pascal's constants. Thermal analysis was carried out on a PerkinElmer Diamond TG/DTA system up to $700^{\circ} \mathrm{C}$ in a static nitrogen atmosphere with a heating rate of $10^{\circ} \mathrm{C} / \mathrm{min}$.

\subsection{Crystal structure determination and refinement}

Single crystal X-ray diffraction data of the iron(II) complex were collected using a Bruker SMART APEX II diffractometer equipped with Mercury CCD detector. The data were collected with graphite monochromated Mo $-\mathrm{K} \alpha$ radiation $(\lambda=0.71073 \AA)$ at $293 \mathrm{~K}$ using $\omega$ scans. The data were reduced using Crystal Clear suite 2.0. ${ }^{22}$ and the space group determination was done using Olex2. The structure was resolved by direct method and refined by full-matrix leastsquares procedures using the SHELXL-2014/7 ${ }^{23}$ software package through OLEX2 suite. ${ }^{24}$

\subsection{Gentisate-1,2-dioxygenase activity of the iron(II)-phenanthroline complex}

To investigate the gentisate dioxygenase activity of the complex, a $10^{-3} \mathrm{M}$ solution of $\mathbf{1}$ in acetonitrile $(\mathrm{MeCN})$ was treated with a $10^{-3} \mathrm{M}$ solution of Gentisic acid (GA) in oxygen saturated $\mathrm{MeCN}$ with two equivalents of triethylamine at room temperature. Absorbance vs. wavelength (wavelength scans) of the solution was recorded at regular time intervals for $3 \mathrm{~h}$ in the wavelength range of 200-900 $\mathrm{nm}$. It may be noted here that a blank experiment without iron(II)-phenanthroline complex (catalyst) did not show any decrement of optical bands and hence, didn't form any cleavage products up to $6 \mathrm{~h}$ in $\mathrm{MeCN}$. The solvent was equilibrated at the atmospheric pressure of $\mathrm{O}_{2}$ at $25^{\circ} \mathrm{C}$ using a known procedure with modifications. ${ }^{25}$ Investigation of dioxygen 
reactivity of the in situ generated $\mathrm{Fe}$-gentisate adduct was carried out in oxygen saturated $\mathrm{MeCN}$ medium at $25^{\circ} \mathrm{C}$. Kinetic analyses ${ }^{26}$ of the gentisate cleavage reactions were carried out by time-dependent measurement of the disappearance of the lower energy GA-to-iron LMCT band at ambient temperature $\left(25^{\circ} \mathrm{C}\right)$ by exposing to molecular oxygen.

\subsection{Determination of salicylate cleavage products}

$0.756 \mathrm{~g}(0.1 \mathrm{mM})$ of the iron(II) complex 1 was reacted with $0.0310 \mathrm{~g}(0.02 \mathrm{mM})$ of $\mathrm{GA}$ in an oxygen saturated $\mathrm{MeCN}$ $(100 \mathrm{~mL})$ at ambient condition and then allowed to slow stir for $18 \mathrm{~h}$. The residue was then treated with $15 \mathrm{~mL}$ of $2 \mathrm{M}$ $\mathrm{HCl}$ and the gentisate cleavage products were extracted with diethylether $(3 \times 10 \mathrm{~mL})$ and dried over anhydrous sodium sulfate. After the removal of solvent, the gentisate cleavage product was quantified and analyzed by HPLC and ${ }^{1} \mathrm{H}$ NMR spectroscopy. ${ }^{1} \mathrm{H}$ NMR data for 2,5-dihydroxybenzoic acid cleavage products $\left(500 \mathrm{MHz}, \mathrm{CDCl}_{3}\right): \delta=2$-oxo-4-hydroxyhepta-3,5-dienedioic acid: $6.65(\mathrm{~d}, 1 \mathrm{H}), 10.81(\mathrm{~s}, 1 \mathrm{H}) ; 6.37$ (dd, 1H), $6.43(\mathrm{~d}, 1 \mathrm{H})$.

\section{Results and Discussion}

\subsection{Synthesis and structural characterization of the $\mathrm{Fe}(\mathrm{II})$ complex (1)}

The tris(phenanthroline)iron(II) nitrate dihydrate complex was synthesized by simple mixing of iron nitrate with phenanthroline ligand in an aqueous medium under stirring condition. The structural formulation was determined through different spectroscopic methods \& analytical techniques. The geometry of the iron(II) complex (1) was determined and confirmed by single crystal $\mathrm{X}$-ray diffraction study.

The IR spectrum of 1 (Figure S1 in Supplementary Information) shows the characteristic patterns for the presence of phenanthroline ligand, nitrate anions and water molecules. Strong characteristic peaks at $\sim 1621$ and $1606 \mathrm{~cm}^{-1}$ corroborate the presence of diimine ligands in $1,{ }^{27}$ while the very strong peak at $1384 \mathrm{~cm}^{-1}$ indicates the existence of nitrate ion. Two splitting peaks at 3541 and 3487 at $\mathrm{cm}^{-1}$ reveal the presence of water molecules in 1. Room temperature magnetic susceptibility analysis reveals the diamagnetic nature of the iron centre as disclosed by $\mu_{\text {eff }}=\sim 0.3 \mathrm{BM}$.

The absorption spectrum of 1 for $1 \times 10^{-4} \mathrm{M}$ acetonitrile solution shows characteristic electronic transitions at 269, 293 and $515 \mathrm{~nm}$. The high energy bands at 269 and $293 \mathrm{~nm}$ are assignable to $n-\pi^{*}$ and $\pi-\pi^{*}$ transitions of the $\mathrm{C}=\mathrm{N}$ chromophore in phenanthroline ligand. Presence of a low-intensity broad band in the visible region at $515 \mathrm{~nm}$ (Figure S2, Abs vs wavelength, $1 \mathrm{~cm}$ optical path length) suggests the existence of octahedral geometry around the iron centre in solution. ${ }^{28}$ The structural integrity in solution state for the iron(II) complex was further confirmed by ESI mass spectral analysis. The ESI mass spectrum of $\mathbf{1}$ in MeCN medium exhibits the molecular ion peak, at $\mathrm{m} / \mathrm{z} 597.41$ as $\left.\left[\mathrm{Fe}(\text { phen })_{3}\right]^{2+}-\mathrm{H}^{+}\right]^{+}$(Figure S3 in Supplementary Information). The absorption bands for the iron(II) complex in solution also remain unaffected over a period of $72 \mathrm{~h}$ which support in favour of stable molecular ion in solution. We have also recorded EPR spectrum of $\mathbf{1}$ in the MeCN medium at room temperature. The EPR spectrum of $\mathbf{1}$ is silent and inactive. This nature of EPR spectrum justifies the low spin state of the iron(II) complex in $\mathrm{MeCN}$ and indicates its diamagnetic nature.

To investigate the electrolytic nature of the complex in $1.0 \times 10^{-3} \mathrm{M} \mathrm{MeCN}$ solution, we have also determined the molar conductance value at room temperature. The value of molar conductivity is found as $197 \mu \mathrm{S} / \mathrm{cm}$ which suggests about 1:2 electrolytic ratio in solution. ${ }^{29}$ This molar conductance value is smaller than that for a normal 1:2 type electrolyte in MeCN. Probably, the existence of water-nitrate cluster in solution lowers the molar conductivity value and accounts for the smaller value.

\subsection{Description of the crystal structure}

We have carried out single crystal X-ray diffraction study to determine the molecular structure of iron(II) complex. The ORTEP diagram of the iron(II) complex is shown in Figure 1. The X-ray crystallographic data and refinement parameters for $\mathbf{1}$ are presented in Table 1. Important bond lengths and angles are summarized in Table 2.

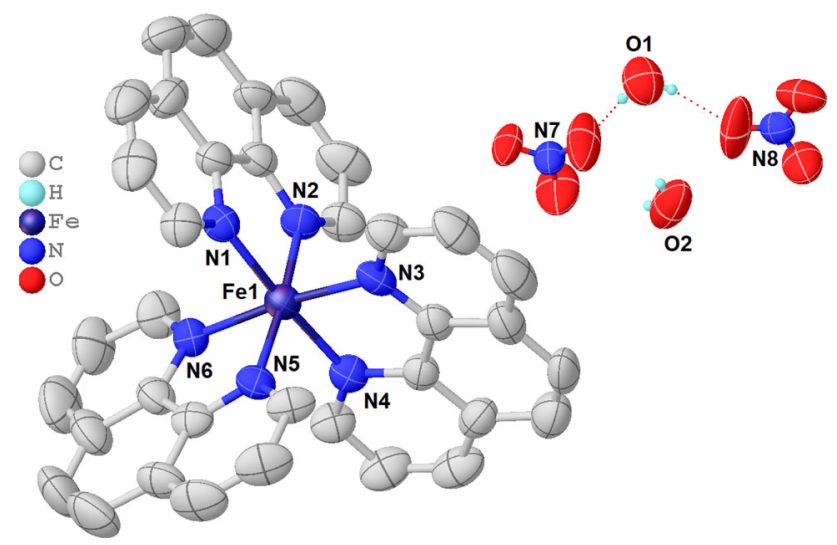

Figure 1. An ORTEP diagram of iron(II)-phenanthroline complex (30\% ellipsoid probability). 
Table 1. Crystallographic refinement parameters of $\left[\mathrm{Fe}(\text { phen })_{3}\right]\left(\mathrm{NO}_{3}\right)_{2} \cdot 2 \mathrm{H}_{2} \mathrm{O}(\mathbf{1})$.

\begin{tabular}{lc}
\hline Parameters & $\mathrm{Fe}(\mathrm{II})$ compound \\
\hline Empirical formula & $\mathrm{C}_{36} \mathrm{H}_{28} \mathrm{~N}_{8} \mathrm{O}_{8} \mathrm{Fe}$ \\
Formula weight & 756.52 \\
Temperature $(\mathrm{K})$ & 293 \\
Crystal system & Triclinic \\
Space group & $P 1^{-}$ \\
$\mathrm{a}(\AA)$ & $8.7902(15)$ \\
$\mathrm{b}(\AA)$ & $12.518(2)$ \\
$\mathrm{c}(\AA)$ & $14.929(3)$ \\
Volume $\left(\AA^{3}\right)$ & $1629.5(5)$ \\
$\mathrm{Z}$ & 2 \\
$\rho\left(\mathrm{gcm}^{-3}\right)$ & 1.542 \\
$\mu\left(\mathrm{mm}^{-1}\right)$ & 0.532 \\
$\mathrm{~F}(000)$ & 780 \\
$\theta$ ranges $\left({ }^{\circ}\right)$ & $3.0^{\circ}-27.50^{\circ}$ \\
$\mathrm{R}_{\text {int }}$ & 0.083 \\
$\mathrm{R}($ reflections $)$ & 17846 \\
wR2 (reflections) & 7451 \\
Final R indices & $0.0873,0.2387$ \\
Largest peak and hole $\left(\mathrm{eA}^{\circ-3}\right)$ & $0.55,-0.38$ \\
\hline
\end{tabular}

X-ray structure of iron(II) complex reveals that the compound crystallizes in a triclinic system with $P 1^{-}$ space group. $\mathrm{Fe}(\mathrm{II})$ ion exists in an octahedral geometry and the hexacoordination is satisfied by six $\mathrm{N}$ atoms of three phen ligands. The Fe1-N5 bond length, 1.978(4) $\AA$, is slightly longer than other $\mathrm{Fe}-\mathrm{N}$ bonds; the average $\mathrm{Fe}-\mathrm{N}$ bond length is $1.966 \AA$ in agreement with previously reported results for analogous compounds. ${ }^{30}$ The bond angles, $\mathrm{N}-\mathrm{Fe}-\mathrm{N}$ and bond lengths of $\mathrm{C}-\mathrm{N}$, and $\mathrm{C}-$ $\mathrm{C}$ in the phenanthroline, all fall within the range of the literature values. ${ }^{31}$

\subsection{Water-nitrate cluster}

Investigation of the crystal packing for the iron(II) complex reveals that layers of the $\left[\mathrm{Fe}(\text { phen })_{3}\right]^{2+}$ cations are separated by the layers of tetrameric water-nitrate clusters (Figure S4 in SI). Both the layers are associated with intermolecular $\mathrm{C}-\mathrm{H} \cdots \mathrm{O}$ hydrogen bonding interactions. But, we had a special interest in waternitrate cluster since this type of association may lead to important insights in the living world. ${ }^{32}$ The intermolecular hydrogen bonding association along $b$-axis among the lattice aqua molecules and counter anionic nitrate

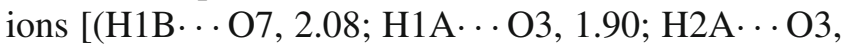
2.39; H2B . O O5, 2.53) Figure 2, Table S1 in SI]. We have also made a comparison between our iron(II) complex with a few structurally related complexes. ${ }^{33}$ To the best of our knowledge, this binding mode among the solvent molecules and counter-anions remains a novel one that was not previously observed. The small $\mathrm{NO}_{3}^{\cdots} \mathrm{H}_{2} \mathrm{O}^{\cdots} \mathrm{NO}_{3}^{\cdots} \mathrm{H}_{2} \mathrm{O}$ cluster grows along $b$ axis mediated via cationic $\mathrm{Fe}$ (II)-phenanthroline units and looks like a zigzag $1 \mathrm{D}$ chain.

We have considered FTIR spectrum to reveal the nature of water-nitrate clusters present in $\mathbf{1}$. The vibrational stretching frequencies for $\mathrm{O}-\mathrm{H}$ bonds of the water-nitrate cluster have been characterized by FTIR analysis of $\mathbf{1}$. A weak broad splitting peaks appear at $3541 \mathrm{~cm}^{-1}$ in the spectrum followed by a broad band centered around $3487 \mathrm{~cm}^{-1}$ (Figure S1 in SI). In our previous work, we observed a $1 \mathrm{D}$ water-nitrate cluster mediated via cobalt(III)-bipyridine complex ${ }^{33 \mathrm{a}}$ and the vibration frequencies for $\mathrm{O}-\mathrm{H}$ bond in waternitrate cluster in cobalt(III)-bipyridine complex resembles well with the $\mathrm{O}-\mathrm{H}$ bond in this water-nitrate cluster in tris(phenanthroline)iron(II) complex. In this

Table 2. Selected bond distances $(\AA)$ and angles $\left({ }^{\circ}\right)$ for $\mathbf{1}$.

\begin{tabular}{|c|c|c|c|}
\hline \multicolumn{4}{|c|}{ Bond distances } \\
\hline N1-Fe1 & $1.966(4)$ & N4-Fe1 & $1.964(4)$ \\
\hline N2-Fe1 & $1.958(4)$ & N5-Fe1 & $1.978(4)$ \\
\hline $\mathrm{N} 3-\mathrm{Fe} 1$ & $1.968(4)$ & N6-Fe1 & $1.967(4)$ \\
\hline \multicolumn{4}{|l|}{ Bond angles } \\
\hline N1-Fe1-N2 & $82.59(17)$ & N2-Fe1-N6 & $92.74(17)$ \\
\hline N1-Fe1-N3 & $95.55(18)$ & $\mathrm{N} 3-\mathrm{Fe} 1-\mathrm{N} 4$ & $82.83(18)$ \\
\hline N1-Fe1-N4 & $174.97(17)$ & N3-Fe1-N5 & $91.59(17)$ \\
\hline N1-Fe1-N5 & $95.12(17)$ & N3-Fe1-N6 & $173.55(17)$ \\
\hline N1-Fe1-N6 & $88.52(16)$ & N4-Fe1-N5 & $89.70(16)$ \\
\hline N2-Fe1-N3 & $92.75(17)$ & N4-Fe1-N6 & $93.52(17)$ \\
\hline N2-Fe1-N4 & $92.71(17)$ & N5-Fe1-N6 & $83.04(17)$ \\
\hline N2-Fe1-N5 & $175.27(17)$ & & \\
\hline
\end{tabular}




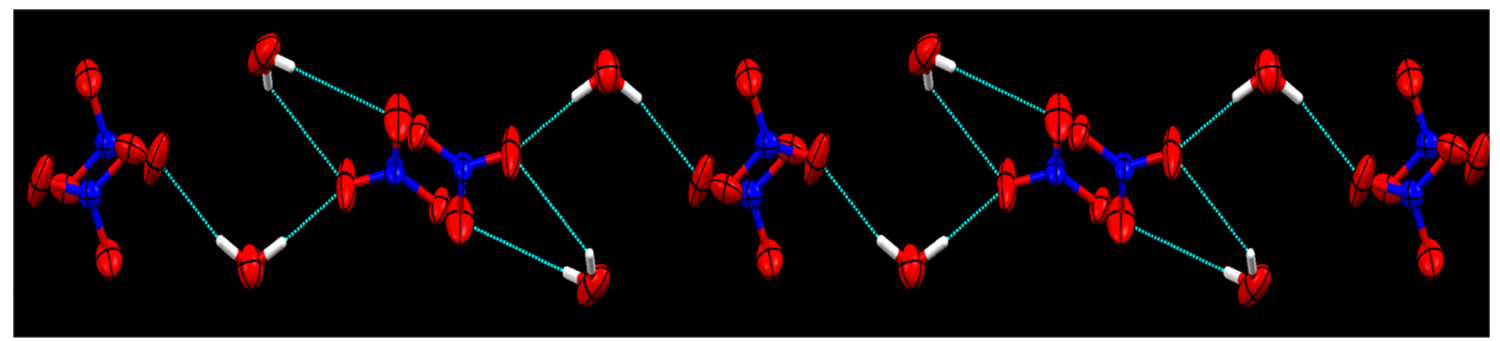

Figure 2. Formation of $\left[\left(\mathrm{NO}_{3}\right)_{2} \cdots\left(\mathrm{H}_{2} \mathrm{O}\right)_{2}\right]$ clusters in the structure of $\mathbf{1}$.<smiles>O=C(O)/C=C/C(O)=CC(=O)C(=O)OC(=O)O</smiles>

Scheme 1. Aromatic ring fission products of GA using Fe(II) complex in oxygenated MeCN.

case, the slight difference in the stretching vibration with the reported work arises from a different mode of self-assembly between lattice water and aqua molecules. ${ }^{33 a, b, c}$

\section{Thermogravimetric analysis}

The thermal properties of $\mathbf{1}$ in nitrogen atmosphere were studied by TG analysis in order to determine its stability. The complex is decomposed in three clearly defined steps with the final residue corresponding to iron oxide. The first step corresponds to the loss of two water molecules at $\sim 103^{\circ} \mathrm{C}($ Figure S4 in SI) while in the second step anionic nitrate ion decomposes at $\sim 300{ }^{\circ} \mathrm{C}$. In the final step, phenanthroline decomposes and the main architecture around metal coordination is lost. This result resembles very well with reported results. ${ }^{33 a, b}$

\subsection{Gentisate dioxygenase activity of the iron(II) phenanthroline complex}

The oxygenation reactions for the iron(II) complex was carried out using 2,5-dihydroxybenzoic acid (GA) as the convenient substrate in acetonitrile (Scheme 1).

The gentisate adducts of iron(II) complex were generated in situ in $\mathrm{MeCN}$, and $\mathrm{O}_{2}$ activation in presence of triethylamine was studied by monitoring the decay of low energy band of GA to Fe LMCT (Figure 3). The in situ generated iron-gentisate adduct in presence of triethylamine reacts with molecular oxygen in the $\mathrm{MeCN}$ medium at ambient conditions over a period of 3 $\mathrm{h}$ and two new visible bands with absorption maximum

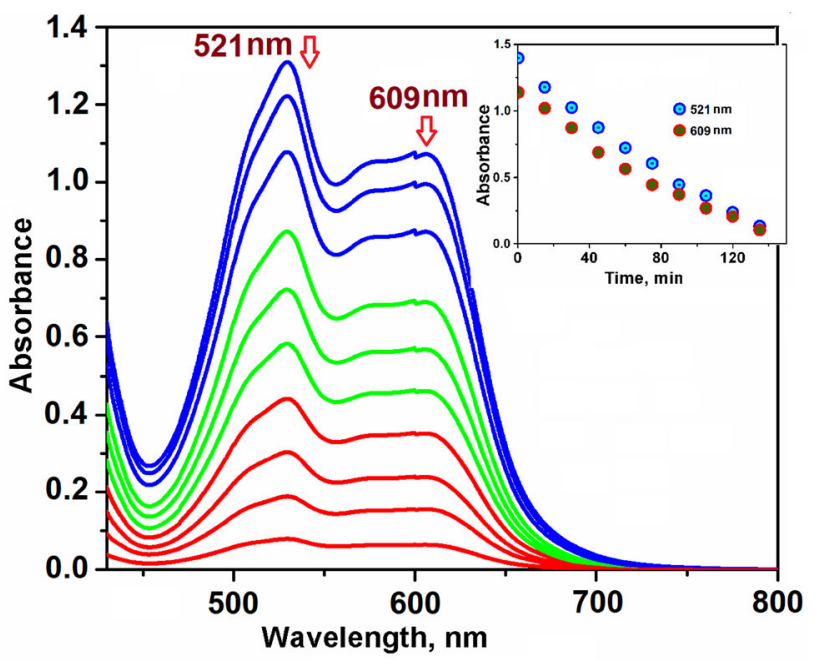

Figure 3. Absorption spectral changes during the reaction of the in situ generated GA-Fe(III) adduct $\left(1 \times 10^{-3} \mathrm{M}\right.$ of 1 and $1 \times 10^{-3} \mathrm{M}$ of GA, $1 \mathrm{~cm}$ optical path length) with $\mathrm{O}_{2}$ (The spectra were recorded after every $15 \mathrm{~min}$ ); Inset: Plot of Abs vs Time.

at 521 and $609 \mathrm{~nm}$ (Figure 3), were observed for the catecholate adduct of complex $\mathbf{1}$. The lower energy bands with decreasing absorbance are attributed to $\mathrm{GA}^{2-}$-toiron LMCT transitions involving two different gentisate ligand orbitals. ${ }^{5,6,34-36 \mathrm{c}}$ As reported in many cases, the energy of the LMCT transitions strongly depends on the nature of the ligands, and it reflects the Lewis acidity of the iron center in the complex. ${ }^{37,38}$ The disappearance of the lower-energy GA-to-iron LMCT band (Figure 4) on oxygenation exhibits pseudo-first-order kinetics, as judged from the linearity of the plot $[1+\log (\mathrm{Abs})]$ versus time ${ }^{6}$ (Figure 4), and the value of $k_{\text {obs }}$ was obtained 


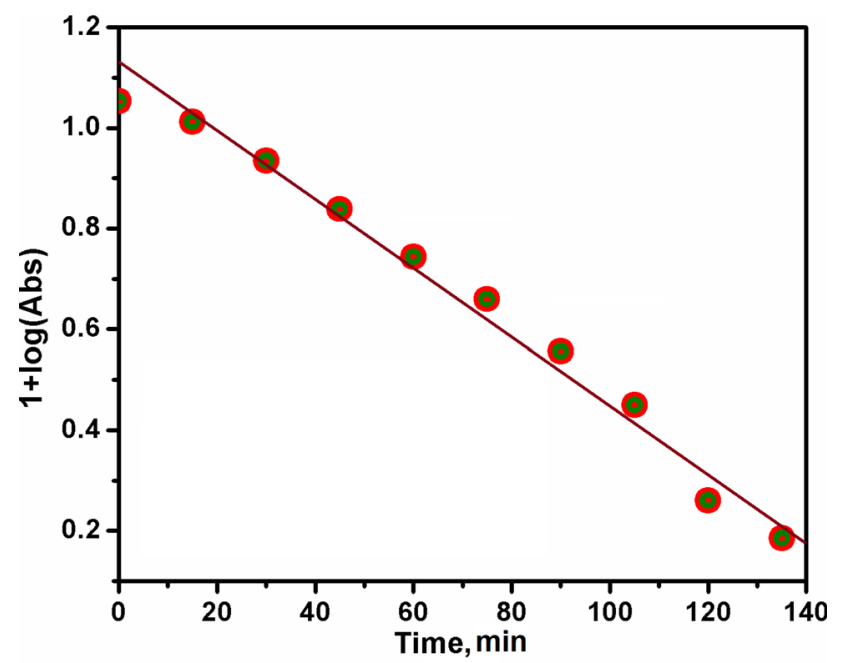

Figure 4. Plot of $[1+\log (\mathrm{Abs})]$ vs time for the reaction of in situ generated GA-Fe(III) adduct with $\mathrm{O}_{2}$ at $25^{\circ} \mathrm{C}$ in MeCN solution. from the slope of the plot. The pseudo-first order rate constant was determined as $k_{\mathrm{obs}}=6.58 \times 10^{-3} \mathrm{~min}^{-1}$.

The purified product was dissolved in $\mathrm{CDCl}_{3}$ and ${ }^{1} \mathrm{H}$ NMR spectrum was recorded. The ${ }^{1} \mathrm{H}$ NMR spectrum produced a set of the characteristic signal for four olefinic protons (Figure S5 in SI). The ${ }^{1} \mathrm{H}$ NMR data thus confirmed the oxidative cleavage of gentisate to 2-oxo4-hydroxy-hepta-3,5-dienedioic acid. The amount of organic product from oxidative cleavage of GA accounts for $\sim 73 \%$ and the remaining $27 \%$ is accounted as inactivated substrate.

In order to evaluate the mechanistic route for the catalytic cycle of gentisate activity by $\mathbf{1}$ (Scheme 2), we have carried out ESI mass spectral analysis of the reaction mixture in acetonitrile medium. The mass spectrum of the reaction mixture in $\mathrm{MeCN}$ solution (Figure S6 in SI) exhibits mainly the characteristic peaks

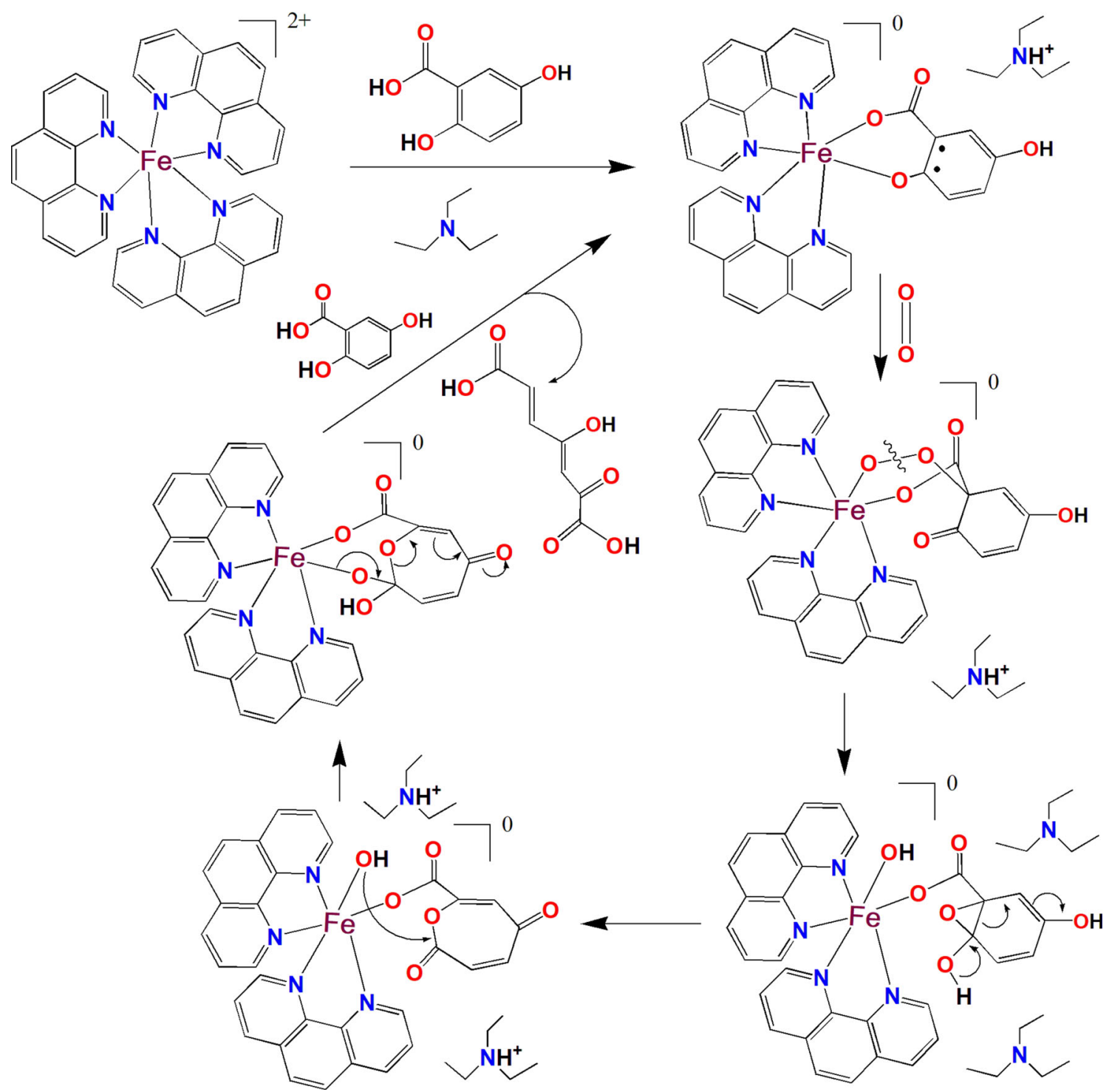

Scheme 2. Proposed mechanistic pathway for gentisate activity by $\mathbf{1}$. 
at $\mathrm{m} / \mathrm{z} 569.07$ and 601.13 with isotope distribution patterns. These characteristic peaks further corroborated the cationic species, $\left[\left(\mathrm{Fe}(\text { phen })_{2}-\mathrm{GA}\right)+\mathrm{H}^{+}\right]$and $\left[\left(\mathrm{Fe}(\mathrm{phen})_{2}-\mathrm{GA}-\mathrm{O}_{2}\right)+\mathrm{H}^{+}\right]$, respectively. Further, the characteristic peak at $\mathrm{m} / \mathrm{z} \sim 569.07$ indicates the presence of coordinated gentisate to iron centre.

Although the iron(II) complex is inert in $\mathrm{MeCN}$ solution, in the presence of GA, one of the three phenanthroline ligands decomposes from the coordination zone of iron(II) centre. The iron-gentisate adduct in the presence of molecular oxygen form a peroxo-iron-gentisate intermediate through substrate activation pathway ${ }^{34-38}$ In our case, probably the facial mode of coordination by gentisate facilitates the formation of peroxo intermediate adopting a pseudo-axial arrangement at iron centre and subsequently, heterolytic $\mathrm{O}-\mathrm{O}$ bond cleavage following Criegee rearrangement affords exclusive production of cleavage product (Scheme 2). Although, extensive experimental studies have to be carried out in order to find mechanistic insights to this gentisate-1,2dioxygenase bio-mimicking activity. Further, scientific reports are limited for such gentisate-1,2-dioxygenase activity by iron(II) complexes and hence, we are not in a position to highlight this activity with recently reported work.

\section{Conclusions}

Herein, we report the synthesis and structural characterization of a new ferroin analogue, [ $\mathrm{Fe}(1,10$-phenanthroline $\left.)_{3}\right]\left(\mathrm{NO}_{3}\right)_{2} \cdot 2 \mathrm{H}_{2} \mathrm{O}(\mathbf{1})$. The lattice water molecules showed unique binding motifs in forming a novel waternitrate cluster, which provides additional stability to the solid. This iron(II) complex has been evaluated as a functional model to mimic the catalytic cycle of gentisate-1,2-dioxygenase enzyme in acetonitrile medium. The iron(II) catalyst exhibits catalytic efficacy in the presence of triethylamine towards gentisic acid and produced exclusively 2-oxohepta-3,5-dienedioic acid at the rate, $k_{\text {obs }}=6.58 \times 10^{-3} \mathrm{~min}^{-1}$ by the involvement of molecular oxygen. This tris(phenanthroline)iron(II) nitrate is an addition to the class of gentisate-1,2dioxygenase with good catalytic activity and functional bio-mimicking efficacy. Further, experiments would be helpful to enlighten the gentisate mimicking activity.

\section{Supplementary Information (SI)}

CCDC 1581209 contains the supplementary crystallographic data for $\mathbf{1}$. These data can be obtained free of charge via http://www.ccdc.cam.ac.uk/conts/retrieving.html or from the Cambridge Crystallographic Data Centre, 12 Union Road, Cambridge CB2 1EZ, UK; fax: (+44) 1223-336-033; or e-mail: deposit@ccdc.cam.ac.uk. Experimental information such as FT-IR spectrum, UV-Vis spectrum, ESI mass spectra, TGA plot, ${ }^{1} \mathrm{H}$ NMR of cleavage products, and $\mathrm{H}$-bonded interaction parameters are available at www.ias.ac.in/chemsci.

\section{Acknowledgements}

BB gratefully acknowledges the financial support by the Science \& Engineering Research Board (SERB), Department of Science and Technology (DST), New Delhi, India under FAST TRACK SCHEME for YOUNG SCIENTIST (No. SB/FT/CS-088/2013 dtd. 21/05/2014).

\section{References}

1. Prince R H 1987 Comprehensive Coordination Chemistry G Wilkinson, J A McCleverty and R Gillard (Eds.) (Oxford: Pergamon) Vol. 5 p. 925; (b) Que L Jr 1989 Iron Carriers and Iron Proteins T M Loehr (Ed.) (New York: VCH) p. 467; (c) Biswas B, Mitra M, Adhikary J, Krishna G R, Bag P P, Reddy C M, Aliaga-Alcalde N, Chattopadhyay T, Das D and Ghosh R 2013 Synthesis, X-ray structural and magnetic characterizations, and epoxidation activity of a new bis $(\mu$-acetato)( $\mu$-alkoxo)dinuclear iron(III) complex Polyhedron 53 264; (d) Pal A, Biswas B, Mitra M, Purohit C S, Hazra S, Kumar G S and Ghosh R 2013 Synthesis, X-ray structure and DNA binding of a mononuclear iron(II) Schiff base complex J. Chem. Sci. 1251161

2. (a) Que L Jr and Ho R Y N 1996 Dioxygen activation by enzymes with mononuclear non-heme iron active sites Chem. Rev. 96 2607; (b) Que L Jr, Lipscomb J D, Münck E and Wood J M 1977 Protocatechuate 3,4-dioxygenase: Inhibitor studies and mechanistic implications Biochim. Biophys. Acta 485 60; (c) Biswas B, Al-Hunaiti A, Räisänen M T, Ansalone S, Leskelä M, Repo T, Chen Y T, Tsai H L, Naik A D, Railliet A P, Garcia Y, Ghosh R and Kole N 2012 Efficient and selective oxidation of primary and secondary alcohols using an iron(III)/phenanthroline complex Eur. J. Inorg. Chem. 4479

3. Feig A L and Lippard S J 1994 Reactions of non-heme iron (II) centers with dioxygen in biology and chemistry Chem. Rev. 94759

4. (a) Chowdhury B, Maji M and Biswas B 2017 Catalytic Aspects of a Copper(II) Complex: biological oxidase to oxygenase activity J. Chem. Sci. 1291627

5. (a) Lipscomb D and Orville A M 1992 Degradation of Environmental Pollutants by Microorganisms and Their Metalloenzymes H Sigel and A Sigel A (Eds.) (New York: Marcel Dekker) Vol. 28 p. 243; (b) Mayilmurugan R, Visvaganesan K, Suresh E and Palaniandavar M 2009 Iron(III) Complexes of tridentate 3N ligands as functional models for catechol dioxygenases: the role of ligand $\mathrm{N}$-alkyl substitution and solvent on reaction rate and product selectivity Inorg. Chem. 48 8771; (c) Dey D and Biswas B 2016 Catechol dioxygenase activity of a mononuclear iron(III)-phenanthroline complex J. Indian Chem. Soc. 93495

6. (a) Dey D, De A, Yadav H R, Guin P S, Choudhury A R, Kole N and Biswas B 2016 An Oxo-Bridged Diiron(II) 
Complex as functional model of catechol dioxygenase ChemistrySelect 01 1910; (b) De A, Garai M, Yadav H R, Choudhury A R and Biswas B 2017 Catalytic promiscuity of an iron(II)-phenanthroline complex Appl. Organometal. Chem. $\mathbf{3 1} 1$

7. (a) Spence E L, Kawamukai M, Sanvoisin J, Braven $\mathrm{H}$ and Bugg T D H 1996 Catechol dioxygenases from Escherichia coli (MhpB) and Alcaligenes eutrophus $(\mathrm{MpcI})$ : sequence analysis and biochemical properties of a third family of extradiol dioxygenases J. Bacteriol. 178 5249; (b) Chatterjee S, Sheet D and Paine T K 2013 Catalytic and regiospecific extradiol cleavage of catechol by a biomimetic iron complex Chem. Commun. 49 10251; (c) Balamurugan M, Vadivelu $\mathrm{P}$ and Palaniandavar $\mathrm{M}$ 2014 Iron (III) complexes of tripodal tetradentate $4 \mathrm{~N}$ ligands as functional models for catechol dioxygenases: the electronic vs. steric effect on extradiol cleavage Dalton Trans. 4314653

8. (a) Bossek U, Hummel H, Weyhermüller T, Bill E and Wieghardt K 1995 The first $\mu(\mathrm{OH})$-bridged model complex for the mixed- valent $\mathrm{Fe}^{\mathrm{II}} \mathrm{Fe}^{\mathrm{III}}$ form of hemerythrin Angew. Chem. Int. Ed. Engl. 34 2642; (b) Crawford R L, Olson P E and Frick T D 1979 Catabolism of 5-chlorosalicylate by a Bacillus isolated from the Mississippi River Appl. Environ. Microbiol. 38379

9. (a) Adachi K, Iwabuchi T, Sano H and Harayama S 1999 Structure of the ring cleavage product of 1-hydroxy2-naphthoate, an intermediate of the phenanthrenedegradative pathway of Nocardioides sp. strain KP7 $J$. Bacteriol. 181 757; (b) Hintner J P, Lechner C, Riegert U, Kuhm A E, Storm T, Reemtsma T and Stolz A 2001 Direct ring fission of salicylate by a salicylate 1,2-dioxygenase activity from Pseudaminobacter salicylatoxidans J. Bacteriol. 1836936

10. (a) Ladd J N 1962 Oxidation of anthranilic acid by a species of Achromobacter isolated from soil Nature 194 1099; (b) Walker N and Lippert K D 1965 Formation of gentisic acid from 2-napthol by a Pseudomonas. Biochem. J. 95 5C; (c) Crawford R L 1975 Degradation of 3-hydroxybenzoate by bacteria of the genus Bacillus. Appl. Microbiol. 30 439; (d) Crawford R L 1976 Pathways of 4-hydroxybenzoate degradation among species of Bacillus. J. Bacteriol. 127 204; (e) Tomasek P H and Crawford R L 1986 Initial reactions of xanthone biodegradation by an Arthrobacter sp. J. Bacteriol. 167 818; (f) Yano K and Arima K 1958 Metabolism of aromatic compounds by bacteria, II. m-Hydroxybenzoic acid hydroxylase $\mathrm{A}$ and $\mathrm{B}$; 5-dehydroshikimic acid, a precursor of protocatechuic acid: a new pathway from salicylic acid to gentisic acid J. Gen. Appl. Microbiol. 4 241

11. Iwabuchi $\mathrm{T}$ and Harayama S 1998 Biochemical and molecular characterization of 1-hydroxy-2-naphthoate dioxygenase from Nocardioides sp. KP7 J. Biol. Chem. 2738332

12. Hintner J P, Reemtsma T and Stolz A 2004 Biochemical and molecular characterization of a ring fission dioxygenase with the ability to oxidize (substituted) salicylate(s) from Pseudaminobacter salicylatoxidans J. Biol. Chem. 27937250

13. Lack L 1959 The enzymic oxidation of gentisic acid Biochim. Biophys. Acta 34117
14. Knox E and Edwards S W 1955 The properties of maleylacetate, the initial product of homogentisate oxidation in liver J. Biol. Chem. 216489

15. Harpel M R and Lipscomb J D 1990 Gentisate 1,2dioxygenase from pseudomonas. Purification, characterization, and comparison of the enzymes from Pseudomonas testosteroni and Pseudomonas acidovorans $J$. Biol. Chem. 2656301

16. Miyauchi K, Adachi Y, Nagata Y and Takagi M 1999 Cloning and sequencing of a novel meta-cleavage dioxygenase gene whose product is involved in degradation of gamma-hexachlorocyclohexane in Sphingomonas paucimobilis J. Bacteriol. 1816712

17. Veldhuizen E J, Vaillancourt F H, Whiting C J, Hsiao M M, Gingras G and Xiao Y 2005 Steadystate kinetics and inhibition of anaerobically purified human homogentisate 1,2-dioxygenase Biochem. J. 386305

18. Harpel M R and Lipscomb J D 1990 Gentisate 1,2dioxygenase from Pseudomonas. Substrate coordination to active site $\mathrm{Fe}^{2+}$ and mechanism of turnover J. Biol. Chem. 26522187

19. Vaillancourt F H, Bolin J T and Eltis L D 2006 The ins and outs of ring-cleaving dioxygenases Crit. Rev. Biochem. Mol. Biol. 41241

20. Gütlich P, Garcia Y and Goodwin H A 2000 Spin crossover phenomena in $\mathrm{Fe}(\mathrm{II})$ complexes Chem. Soc. Rev. 29419

21. Childs B J, Craig D C, Scudder M L and Goodwin H A 1998 Structural and electronic studies of the coordination of 6-(thiazol-2-yl)-2, 2'-bipyridine and related systems to $\mathrm{Fe}(\mathrm{II}), \mathrm{Co}(\mathrm{II})$ and $\mathrm{Ni}(\mathrm{II})$ Inorg. Chim. Acta 27432

22. CrystalClear 2.0; Rigaku Corporation: Tokyo, Japan

23. Sheldrick G M 2008 Crystal structure refinement with SHELXL Acta Cryst. A64 112

24. Dolomanov O V, Bourhis L J, Gildea R J, Howard J A $\mathrm{K}$ and Puschmann H 2009 OLEX2: A complete structure solution, refinement and analysis program J. Appl. Cryst. 42339

25. Sawyer D T 1991 Oxygen Chemistry (New York: Oxford University Press)

26. Halder P, Paria S and Paine T K 2012 Dioxygen reactivity of biomimetic iron-catecholate and iron-o-aminophenolate complexes of a tris(2-pyridylthio)methanido ligand: Aromatic $\mathrm{CC}$ Bond cleavage of catecholate versus oiminobenzosemiquinonate radical formation Chem. Eur. J. 1811778

27. Nakamoto K 1997 Infrared and Raman Spectra of Inorganic and Coordination Compounds part B: Applications in Coordination, Organometallic and Bioinorganic Chemistry (New York: John Wiley \& Sons Inc.)

28. Solé J G, Bausá L E and Jaque D 2005 An Introduction to Optical Spectroscopy of Inorganic Solids (UK: John Wiley \& Sons Ltd.)

29. Biswas B and Sengupta P S 2017 An iron(III)-Schiff base complex as a functional model of phenoxazinone synthase enzyme J. Indian Chem. Soc. 94571

30. (a) Wang Q X, Jiao K W, Sun F F and Jian X H 2006 Recent developments in recyclable copper catalyst systems for $\mathrm{C}-\mathrm{N}$ bond formingcross-coupling reactions using aryl halides and arylboronic acids Eur. J. Inorg. Chem. 1838; (b) Dey D, Das S, Yadav H R, Ranjani A, 
Gyathri L, Roy S, Guin P S, Dhanasekaran D, Choudhury A R, Akbarsha M A and Biswas B 2016 Design of a mononuclear copper(II)-phenanthroline complex: Catechol oxidation, DNA cleavage and antitumor properties Polyhedron 106 106; (c) De A, Dey D, Yadav H R, Maji M, Rane V, Kadam R M, Roy Choudhury A and Biswas B 2016 Unprecedented hetero-geometric discrete copper(II) complexes: Crystal structure and bio-mimicking of Catecholase activity J. Chem. Sci. 1281775

31. (a) Tian Y P, Duan C Y, Xu X X and You X Z 1995 Screw-chain structure of 1,10-phenanthroline hydrate, $\mathrm{C}_{12} \mathrm{H}_{8} \mathrm{~N}_{2} \cdot \mathrm{H}_{2} \mathrm{O}$ Acta Crystallogr. Sect. C 51 2309; (b) Dey D, Roy A B, Shen C -Y, Tsai H -L, Ranjani A, Gayathri L, Chandraleka S, Dhanasekaran D, Akbarsha M A, Kole N and Biswas B 2015 Synthesis and bio-catalytic activity of isostructural cobalt(III)-phenanthroline complexes J. Chem. Sci. 127 649; (c) Garai M, Dey D, Maji M, Yadav H R, Choudhury A R and Biswas B 2017 Synthesis and phosphatase activity of a cobalt(II)phenanthroline complex J. Chem. Sci. 1291513

32. E Westhoff (Ed.) 1993 Water and Biological Macromolecules (Boca Raton: CRC Press)

33. (a) Das S, Pasan J, Ranjani A, Gayathri L, Saha S, Chandraleka S, Dhanasekaran D, Pasan J, Maji M, Akbarsha M A and Biswas B 2016 Recognition of self-assembled water-nitrate cluster in a $\mathrm{Co}(\mathrm{III})-2,2$ '-bipyridine host: Synthesis, crystal structure, DNA cleavage, molecular docking and anticancer activity J. Chem. Sci. 128 1755; (b) Dey D, Pal S, Yadav H R, Sengupta P S, A R Choudhury, Kole N and Biswas B 2015 Unusual crystallographic existence of hydrated zinc(II) bisulphate complex: An experimental \& theoretical observations RSC Adv. 542681

34. (a) Stolz A, Nörtemann B and Knackmuss H J 1992 Bacterial metabolism of 5-aminosalicylic acid. Initial ring cleavage Biochem. J. 282 675; (b) Lendenmann U and Spain J C 1996 2-aminophenol 1,6-dioxygenase: a novel aromatic ring cleavage enzyme purified from $P$ seudomonas pseudoalcaligenes JS45 J. Bacteriol. 1786227 ; (c) Kurahashi T, Oda K, Sugimoto M, Ogura T and Fujii H 2006 Trigonal-bipyramidal geometry induced by an external water ligand in a sterically hindered iron salen complex, related to the active site of protocatechuate 3,4-dioxygenase Inorg. Chem. 45 7709; (d) Merkel M,
Müller F K and Krebs B 2002 Novel iron (III) complexes with phenolate containing tripodal tetradentate ligands as model systems for catechol 1,2-dioxygenases Inorg. Chim. Acta 337308

35. Pascaly M, Duda M, Schweppe F, Zurlinden F, Muller K and Krebs B 2001 The systematic influence of tripodal ligands on the catechol cleaving activity of iron (III) containing model compounds for catechol 1,2-dioxygenases J. Chem. Soc. Dalton Trans. 828

36. Koch W O and Kruger H J 1995 A highly reactive and catalytically active model system for intradiolcleaving catechol dioxygenases: structure and reactivity of iron(III) catecholate complexes of $N, N^{\prime}$-dimethyl2,11-diaza[3.3](2,6)pyridinophane Angew. Chem. Int. Ed. Engl. 342671

37. (a) Takenaka S, Murakami S, Shinke R, Hatakeyama K, Yukawa H and Aoki K 1997 Novel genes encoding 2-aminophenol 1,6-dioxygenase from Pseudomonas species AP-3 growing on 2-aminophenol and catalytic properties of the purified enzyme J. Biol. Chem. 272 14727; (b) Ito M and Que L Jr 1997 Biomimetic extradiol cleavage of catechols: Insights into the enzyme mechanism Angew. Chem. Int. Ed. Engl. 36 1342; (c) Cox D, Benkovic S J, Bloom L M, Bradley F C, Nelson M J, Que L Jr. and Wallick D E 1988 Catecholate LMCT bands as probes for the active sites of nonheme iron oxygenases J. Am. Chem. Soc. 1102026

38. (a) Muraki T, Taki M, Hasegawa $\mathrm{Y}$, Iwaki $\mathrm{H}$ and Lau P C 2003 Prokaryotic homologs of the eukaryotic 3-hydroxyanthranilate 3,4-dioxygenase and 2-amino-3carboxymuconate-6-semialdehyde decarboxylase in the 2-nitrobenzoate degradation pathway of Pseudomonas fluorescens strain KU-7 Appl. Environ. Microbiol. 69 1564; (b) Funabiki T, Mizoguchi A, Sugimoto T, Tada S, Tsuji M, Sakamoto H and Yoshida S 1986 Oxygenase model reactions: Intra-and extradiol oxygenations of 3,5-di-tert-butylcatechol catalyzed by (bipyridine)(pyridine)iron(III) complex J. Am. Chem. Soc. 108 2921; (c) Die A, Gatteschi D and Pardi L 1993 Synthesis, characterization, and reactivity of catecholato adducts of iron(III) triaza- and tetraazamacrocyclic complexes: chemical evidence of the role of the metal ion in the oxidative cleavage Inorg. Chem. 32 1389 